\title{
Karakterisasi Dan Sifat Kemagnetan Pasir Besi Ekstraksi Asal Pantai Betaf Sarmi, Papua
}

\author{
Endang Haryati *1, Khaerian Dahlan ${ }^{2}$, Shabri Putra Wirman ${ }^{3}$ \\ 1,2 Program Studi Fisika, Universitas Cenderawasih, Jayapura Papua, Indonesia \\ ${ }^{3}$ Program Studi Fisika, Universitas Muhammadiyah Riau, Pekanbaru, Riau, Indonesia \\ ${ }^{*}$ Email : endanghfis@gmail.com
}

\begin{abstract}
Abstrak
Karakterisasi dan pengujian sifat kemagnetan pasir besi ekstraksi asal pantai betaf Sarmi Papua telah dilakukan. Tujuan dari penelitian ini adalah untuk menentukan kandungan mineral, fasa senyawa besi dan sifat kemagnetan dari pasir besi ekstraksi yang beasal dari pantai Betaf Sarmi Papua menggunakan alat XRF, XRD dan VSM. Hasil penelitian menunjukkan bahwa pasir besi ekstraksi mengandung 43,81\% of besi (Fe), 25,75\% silika (Si) and 30,44 \% mineral lainnya. Puncak tertinggi grafik XRD merupakan senyawa magnetit $\left(\mathrm{Fe}_{3} \mathrm{O}_{4}\right)$ yaitu pada $2 \theta=35,65^{\circ}$. Kurva histerisis VSM menunjukkan bahwa pasir besi ekstraksi asal pantai Betaf Sarmi Papua merupakan material superparamagnetik dengan/nilai magnetisasi saturasi maksimum (Ms) sebesar 4,54 emu/gr, magnetisasi remanen (Mr) sebesar 0,371 emu/gr dan nilai medan koersivitas sebesar 208 0e.
\end{abstract}

Kata kunci : pasir besi ekstrasi, kandungan mineral, sifat kemagnetan

\section{Abstract}

Characterization and magnetic behavior test of extracted iron sand from Betaf beach of Sarmi Papua was studied. The purpose of the recearch was to determine minerals content, phase of iron compound, and magnetic behavior of extracted iron sand from Betaf beach of Sarmi Papua were caculate using XRF, XRD and VSM. The result showed that extrated iron sand was contained $43,81 \%$ of Iron ( $\mathrm{Fe}$ ), 25,75\% of Silika (Si) and 30,44\% others. The XRD pattern showed that the highest peak was magnetite $\left(\mathrm{Fe}_{3} \mathrm{O}_{4}\right)$ at $2 \theta=35,65^{\circ}$. The histerisis curve of VSM showed that extracted iron sand from Betaf beach of Sarmi Papua was superparamagnetic material where maximum saturation magnetization (Ms) value of 4,54 emu/gr, remanen magnetization (Mr) value of 0,371 emu/gr and coercivity field (Hc) value of 208 Oe.

Keywords: extracted iron sand, minerals content, magnetic behavior

\section{PENDAHULUAN}

Sarmi merupakan salah satu kabupaten di Papua, Indonesia yang kaya akan pasir hitam atau disebut sebagai pasir besi baik di sungainya maupun pantainya. Kandungan utama pasir asal pantai Betaf Sarmi adalah 41,68 \% Silika (Si), 33,84 \% besi (Fe) dan 24,48 \% mineral lainnya [Haryati E, 2018].

Pasir besi asal sungai Batang Kuranji Padang Sumatra Barat memiliki presentase massa pasir besi antara 5,01\% dan 20,26\%, se da ng ka n mineral yang terdapat dalam pasir besi adalah albite ( $\mathrm{NaAlSi} 308)$, magnetite (Fe304), squart ( $\left.\mathrm{SiO}_{2}\right)$, halloysite $\left(\mathrm{Al}_{2} \mathrm{Si} 2 \mathrm{O}_{5}(\mathrm{OH})_{42} \mathrm{H}_{2} \mathrm{O}\right)$, saponite $\left(\mathrm{CaO}_{2}\right.$ Mg3(SiAl)4 010(OH)2 4H2O) dan pyrophyllite (Al2O3 4SiO2 H2O) [Afdal \& Niarti, L, 2013]. Pasir besi asal pantai Logending Kabupaten Kebumen, Jawa Tengah mengandung mineral magnetik hematit ( $\left.\mathrm{Fe}_{2} \mathrm{O}_{3}\right)$ dengan kadar mineral magnetik sekitar 4,05\% [Bilalodin, 2010]. Kandungan mineral pasir pantai Ambal Kecamatan Mirit Kabupaten Kebumen berbentuk senyawa Magnetite (Fe304) dan 
Hematite ( $\left.\mathrm{Fe}_{2} \mathrm{O}_{3}\right)$ [Bilalodin, Sunardi \& Effendy, M. 2013]. Mineral berat pada pasir kali asal sungai Bramaputra Bangladesh mengandung titanium besi, magnetite $\left(\mathrm{Fe}_{2} \mathrm{O}_{4}\right)$ and ilmenite $\left(\mathrm{FeTiO}_{3}\right)[\mathrm{Md}$. Ibrahim Khalil, dkk. 2016].

Tujuan dari penelitian ini adalah menentukan karakterisasi dan sifat kemagnetan pasir besi yang diekstraksi dengan magnet permanen yang berasal dari Pantai betaf Sarmi Papua.

\section{METODE PENELITIAN}

\section{Alat dan Bahan}

Bahan penelitian berupa pasir hitam asal pantai Betaf Sarmi, Papua dan aquades. Sedangkan alat yang digunakan dalam penelitian ini berupa alumunium foil, timbangan digital, grinder, mortar, ayakan 100 mesh, magnet permanen, magnetik stirer, wadah plastik, plastik transparan. Karakterisasi sampel menggunakan alat Vibrating Sample Magnetic (VSM), X-Ray Fluorosence (XRF) dan X-Ray Diffraction (XRD).

\section{Prosedur Penelitian}

Sampel pasir yang telah diambil dari pantai betaf Sarmi, Papua pertama-tama dicuci dengan aquades sampai bersih lalu dikeringkan dibawah sinar matahari hingga kering. Kemudian sampel dihaluskan dengan grinder dan mortar lalu diayak dengan ayakan 100 mesh. Sampel yang telah diayak kemudian diekstraksi menggunakan magnet permanen dan magnetik stirer untuk memperoleh pasir besi yang lebih murni. Hasil ekstraksi pasir besi kemudian di masukan kedalam wadah sampel dan dikirim ke Badan Tenaga Nuklir Nasional Serpong untuk pengujian menggunakan VSM dan ke ITS Surabaya untuk pengujian XRD dan XRF.

\section{HASIL DAN PEMBAHASAN}

Hasil penelitian yang diperoleh berupa presentase kandungan mineral pasir besi ekstraksi yang diuji dengan XRF, bentuk senyawa magnetik pasir besi yang diuji dengan XRD dan grafik histerisis VSM yang menjunjukan sifat magnetik material.

Tabel 1. Kandungan mineral pasir besi ekstraksi asal pantai Betaf Sarmi Papua

\begin{tabular}{cccc}
\hline Unsur & Presentase (\%) & Senyawa Oksida & Presentase (\%) \\
\hline $\mathrm{Fe}$ & 43,81 & $\mathrm{Fe} 203$ & 33,38 \\
$\mathrm{Si}$ & 25,75 & $\mathrm{SiO} 2$ & 37,60 \\
$\mathrm{Ca}$ & 14,00 & $\mathrm{CaO}$ & 11,85 \\
$\mathrm{Al}$ & 6,10 & $\mathrm{Al} 203$ & 8,4 \\
$\mathrm{~K}$ & 5,06 & $\mathrm{~K} 20$ & 3,975 \\
$\mathrm{Ti}$ & 2,46 & $\mathrm{TiO} 2$ & 2,365 \\
lainnya & 2,82 & lainnya & 2,43 \\
\hline
\end{tabular}


Dari tabel 1 dapat diketahui bahwa kandungan mineral besi pada pasir besi memiliki presentasi yang paling besar dibanding dengan mineral lainnya yaitu 43,81 \%. Pasir besi ekstraksi asal pantai Betaf Sarmi masih mengandung mineral Silika 25,75 \%, 14,00\% Calsium dan mineral lainnya dengan presentase yang kecil.

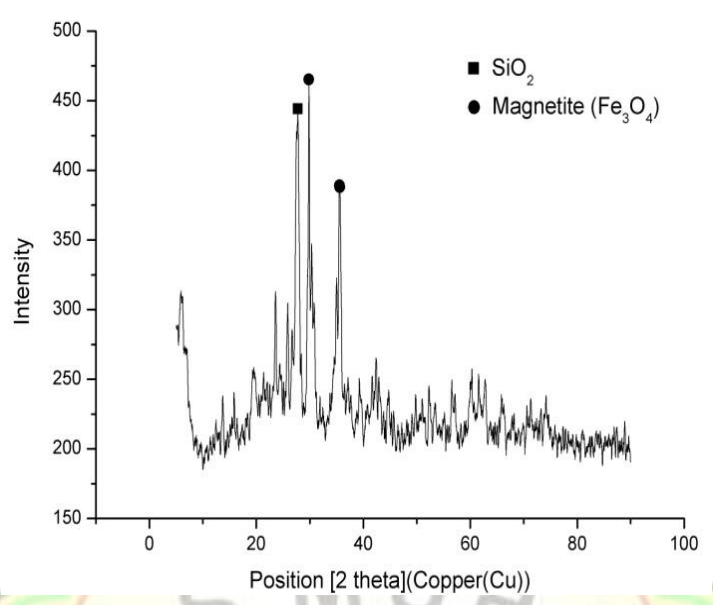

Gambar 1. Grafik XRD pasir besi ekstraksi asal pantai Betaf Sarmi, Papua

Gambar 1 merupakan grafik analisis XRD pasir besi ekstraksi asal pantai Betaf Sarmi Papua yang menunjukkan bahwa puncak tertinggi XRD pada $2 \theta=35,65^{\circ}$ merupakan senyawa Magnetit $\left(\mathrm{Fe}_{3} \mathrm{O}_{4}\right)$. Senyawa lainnya yang memiliki puncak cukup tinggi adalah senyawa Silika $\left(\mathrm{SiO}_{2}\right)$ quartz.

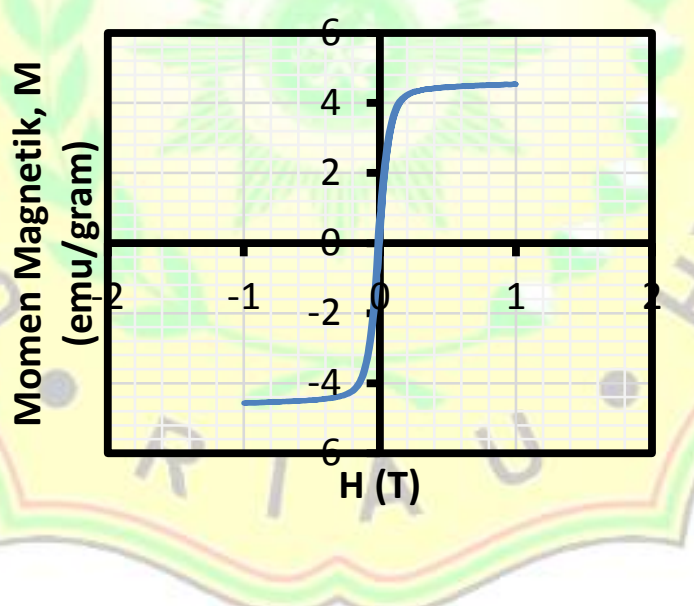

Gambar 2. Grafik histerisis VSM pasir besi ekstraksi asal pantai Betaf Sarmi, Papua

Gambar 2 menunjukkan kurva histerisis yang diukur pada suhu ruang untuk sampel pasir besi ekatraksi asal Sarmi. Grafik tersebut menunujukkan bahwa sampel tersebut memiliki nilai magnetisasi saturasi maksimum (Ms) sebesar 4,54 emu/gram pada nilai H maksimum sebesar 1T, magnetisasi remanen (Mr) sebesar 0,371 emu/gram dan nilai medan koersivitas sebesar 208 Oe. Dari grafik tersebut terlihat bahwa pasir besi asal pantai Betaf Sarmi merupakan material superparamagnetik.

\section{KESIMPULAN}

Pasir besi ekstraksi asal pantai Betaf Sarmi mengandung besi (Fe) sebesar 43,81\%, sebesar 43,81\%, 25,75\% Silika (Si) dan 30,44 \% mineral lainnya. Analisis grafik XRD menunjukan bahwa fasa dominan 
dalam pasir besi ekstraksi yang berasal dari pantai Betaf Sarmi merupakan senyawa magnetit (Fe304).

Parameter kurva histerisis yang diukur pada suhu ruang menunjukan bahwa pasir besi ekstraksi asal Sarmi merupakan material superparamagnetik.

\section{UCAPAN TERIMA KASIH}

Penulis menyampaikan terima kasih kepada Lembaga Penelitian dan Pengabdian kepada Masyarakat (LPPM) Universitas Cenderawasih yang telah memberikan biaya penelitian melalui PNBP Universitas Cenderawasih tahun 2018.

\section{DAFTAR PUSTAKA}

Haryati, E \& Dahlan, K. 2018. Potential of iron sand from Betaf beach, Sarmi regency and river sand from Doyo, Jayapura regency, Papua as basic materials of mortar as nuclear radiation shielding. Journal of Physics conference series 997012043

Afdal \& Niarti, L. 2013. Karakterisasi Sifat Magnetik Sungai Batang Kuranji Padang Sumatra Barat. Jurnal Ilmu Fisika vol.5, No.1, Maret 2013 hal 24-30,ISSN : 1979-4657

Bilalodin.2010. Kajian Sifat Magnetik Dari Pasir Besi Pantai Logending Kabupaten Kebumen. Jurnal Molekul Vol.5 No.2, hal $105-108$

Bilalodin, Sunardi \& Effendy, M. 2013. Analisis Kandungan Senyawa Kimia dan Uji Sifat Magnetik Pasir Besi Pantai Ambal. Jurnal Fisika Indonesia No.50 Vol. XVII, hal 29-31, Agustus 2013, ISSN : 1410-2994 Md. Ibrahim Khalil, dkk. 2016. Heavy Minerals in Sands along Brahmaputra (Jamuna) River of Bangladesh. International Journal of Geosciences, 2016,7,47-52

Garry, M.,R Mc Afree. Jr., C.L. Wolf. 1972. Glossary Of Geology.Washington DC. 